\title{
Takotsubo Syndrome: Uncovering Myths and Misconceptions
}

\author{
Victoria L. Cammann ${ }^{1}$ • Michael Würdinger ${ }^{1}$. Jelena R. Ghadri ${ }^{1}$. Christian Templin ${ }^{1}$
}

Accepted: 4 May 2021 / Published online: 16 July 2021

(C) The Author(s) 2021

\begin{abstract}
Purpose of Review Takotsubo syndrome (TTS) was described in Japan 3 decades ago to affect predominately postmenopausal women after emotional stress. This history is the basis of commonly held beliefs which may contribute to the underdiagnosis and misperception of TTS.

Recent Findings TTS affects not only women, but can be present in both sexes, and can appear in children as well as in the elderly. TTS is characterized by unique clinical characteristics with morphological variants, and incurs a substantial risk for recurrent events and adverse outcomes. Physical triggers are more common than emotional triggers and are major disease determinants. TTS seems not to be completely transient as patients report ongoing chest pain, dyspnea, or fatigue even after months of the acute event.

Summary Knowledge of the clinical features and outcomes of TTS patients has evolved substantially over the past decades. The heterogeneous appearance of TTS needs to be recognized in all medical disciplines to maximize therapy and improve outcomes.
\end{abstract}

Keywords Takotsubo syndrome $\cdot$ Broken heart syndrome $\cdot$ International Takotsubo Registry $\cdot$ Risk stratification $\cdot$ Outcome

\section{Introduction}

In 1991, Sato and colleagues from the Hiroshima City Hospital reported 5 cases of women who presented with an unusual left ventricular (LV) wall motion pattern after severe emotional stress $[1,2]$. The unique morphological feature of the LV, with shared similarities to a Japanese octopus trap (narrow neck and wide bottom), led the Japanese cardiologists

Victoria L. Cammann and Michael Würdinger contributed equally to this work.

Topical Collection on Women and Ischemic Heart Disease

Christian Templin

christian.templin@usz.ch

Victoria L. Cammann

victorialucia.cammann@usz.ch

Michael Würdinger

michael.wuerdinger@usz.ch

Jelena R. Ghadri

jelena-rima.templin-ghadri@usz.ch

1 Andreas Grüntzig Heart Catheterization Laboratories, Department of Cardiology, University Heart Center, University Hospital Zurich, Raemistrasse 100, 8091 Zurich, Switzerland to term this cardiac entity "takotsubo." Since the seminal observation, takotsubo syndrome (TTS) has emerged as an important differential diagnosis of patients presenting with acute chest pain. This review focuses on widely held myths and misconceptions to amplify perception of TTS (Fig. 1).

\section{Definition}

Takotsubo syndrome is an acute heart failure syndrome characterized by LV systolic dysfunction [3-5]. Patients with TTS may present with typical acute coronary syndrome (ACS) symptoms including chest discomfort or dyspnea, STsegment deviations on electrocardiogram, and cardiac biomarker abnormalities [6]. Cardiac catheterization is the cornerstone of diagnosis to differentiate TTS from other etiologies such as ACS or myocardial infarction without obstructive coronary arteries (MINOCA) [7-9]. The pathophysiology of TTS is not well understood, and enhanced sympathetic stimulation and elevated circulating catecholamines were first suggested to be major mediators [10]. The pathophysiology likely involves a complex interplay of central autonomic dysfunction, hormones, multi-vessel coronary spasm, microvascular dysfunction, and inflammation [11•]. 


\begin{tabular}{|c|c|c|}
\hline & Previous notion & Current evidence \\
\hline Terminology & Takotsubo cardiomyopathy & Takotsubo syndrome \\
\hline \multirow[t]{5}{*}{ Epidemiology } & Rare disease & Possibly underdiagnosed \\
\hline & Japan & Global burden \\
\hline & Asian descent & Various ethnic groups and races \\
\hline & Women & Both sexes $\left(q>>0^{\lambda}\right)$ \\
\hline & Elderly & All age groups \\
\hline \multirow[t]{4}{*}{ Triggering factors } & Emotional triggers & Physical, emotional, both or no triggering factor \\
\hline & Negative life events & Negative and pleasant life events \\
\hline & Absence of pheochromocytoma & Phaeochromocytoma can be present \\
\hline & Absence of neurologic injury & Acute neurologic disorders can be present \\
\hline Morphological variants & Apical ballooning & Apical, midventricular, basal and focal form \\
\hline Coronary artery disease & Absence of coronary artery disease & Coronary artery disease can be present \\
\hline Outcome & Benign prognosis & Substantial morbidity and mortality \\
\hline Recovery & Complete recovery & Concept of "incomplete recovery" \\
\hline
\end{tabular}

Fig. 1 Evolution and paradigm shifts of takotsubo syndrome.

\section{Terminology}

Over the past years, more than 70 names have been introduced how to call this cardiac condition, further underpinning the diversity and heterogeneity of features $[12,13]$. The most popular names are "broken heart syndrome," "stress cardiomyopathy," or "apical ballooning syndrome." None of them universally reflects the spectrum of presentation and morphological features and includes inherent limitations which may have contributed to misconceptions and misdiagnosis. The term "broken heart syndrome" implies that negative emotional or psychological triggering factors such as the loss of a beloved person are mandatory to be present. Likewise, the term "stress cardiomyopathy" suggests that the disease must occur in the presence of a triggering event. "Apical ballooning" implies that the classical apical ballooning is the only existing morphological variant of TTS $[12,14 \bullet \bullet]$.

TTS was originally designated as a primary acquired cardiomyopathy by the American Heart Association and as an unclassified cardiomyopathy by the European Society of Cardiology $[15,16]$. With more advanced understanding of the disease, it has become apparent that TTS does not share common characteristics of non-ischemic cardiomyopathies and that it might more likely represent a microvascular form of ACS [17]. Based on clinical experience and advances in clinical science and in acknowledgment of the Japanese investigators, there is now international consensus that the most suitable name is "takotsubo syndrome" [14••].

\section{Epidemiologic Features}

An estimated $4 \%$ of patients who are admitted with signs and symptoms of an ACS are diagnosed as TTS [18-20]. The true incidence of TTS is likely to be higher due to underreporting and misdiagnosis of TTS cases [21]. TTS shows a strong predilection for females (9:1 female-to-male ratio), and more than $80 \%$ of patients involve females over the age of 50 years $[6,22,23]$. The mean age of women at TTS diagnosis is around 67 years and 63 years for men [6]. TTS was completely underrecognized in most parts of the world until first reports from the USA and France were published nearly 10 years after the initial description in Japan [24, 25]. TTS now represents a global disorder affecting both sexes, all age groups, and various ethnic groups and races.

\section{Life Event Triggers for TTS}

TTS is characteristically triggered by emotional or physical inciting events. However, absence of triggering factors does not preclude the diagnosis of TTS. Negative emotional life 
events have unequivocally been acknowledged as the prototypical provocation for TTS. In earlier years, physical factors (e.g., traumata, surgery, or medical conditions) were not known to trigger TTS. Similarly, it was inconceivable that TTS could also occur in the absence of stressful life events or in the presence of both emotional and physical stress. In the InterTAK Registry, only $28 \%$ of patients had emotional triggering factors [6]. Physical triggering factors were more prevalent than emotional triggers and were more common in men. Notably, one-third of patients had the absence of identifiable triggering events [6]. In 2016, a novel conceptual entity termed as the "happy heart syndrome" was described adding pleasant life events to the heterogeneous spectrum of triggering events [26]. This concept has presented an additional paradigm shift beyond the commonly accepted spectrum of inciting events.

\section{Pheochromocytoma as a Trigger for TTS}

Pheochromocytoma is a catecholamine-releasing adrenal tumor [27]. The incidence of pheochromocytoma is generally low ( $<1 \%$ per 100,000 patients' years) but has increased due to intensified imaging and biochemical testing over recent years [28]. The clinical presentation of patients with pheochromocytoma encompasses an extremely broad spectrum and can range from hypertensive crisis to severe hypotension with shock $[27,29]$. Nearly all diagnostic criteria for TTS have excluded pheochromocytoma as a trigger [30-35]. TTS due to pheochromocytoma has comparable clinical features and imaging and histopathological findings to TTS triggered by physical or emotional stress [36, 37]. Based on current evidence, there is no obvious reason to exclude excessive catecholamine release from pheochromocytoma as a possible triggering factor for TTS [37, 38••].

\section{Neurologic Disorders as Triggers for TTS}

Cardiac abnormalities are frequently observed after neurologic disorders such as stroke, subarachnoid hemorrhage, or epilepsy [39-42]. The mechanism of developing TTS may be related to increased concentrations of catecholamines after neurologic disorders, which may cause myocardial injury [43, 44]. The initial version of the Mayo Clinic Diagnostic criteria excluded the presence of head trauma or intracranial bleeding for diagnosis of TTS [32]. However, advances in clinical science have uncovered that neurologic disorders are important triggering factors of TTS and constitute $16 \%$ of all physical triggers [6, 45-47]. Intriguingly, the prevalence of (acute or past) neurologic disorders is 2 times higher in TTS patients compared to age- and sex-matched controls with ACS [6]. More recently, functional magnetic resonance imaging studies demonstrated alterations of brain regions (central autonomic network), further highlighting the importance of the brain-heart axis in the development of TTS [48-50]. Thus, the association between neurologic disorders and TTS is not only for the cardiologists but also for all clinicians to recognize.

\section{Diagnosis}

Diagnostic criteria for TTS were proposed from multiple centers in various countries $[30,33-35,51,52]$. In 2018 , the InterTAK Diagnostic Criteria were developed with consensus from 36 experts to provide standardized diagnostic criteria incorporating the most recent and updated evidence available for TTS $[\bullet \cdot$. The InterTAK Diagnostic Criteria added neurologic disorders, the presence of coronary artery disease, and pheochromocytoma as inclusion criteria to improve diagnosis of TTS (Table 1) [••]. TTS diagnosis is particularly challenging in "special populations" such as children, in patients with neurologic disorders, and in patients without ECG deviations. In such cases, serial measurements of cardiac biomarkers and echocardiography should be performed to increase the sensitivity of TTS. Coronary angiography with ventriculography is the cornerstone of diagnosis to exclude critical coronary lesions which are the culprits for wall motion abnormalities [8]. Coronary computed tomography can be performed in patients

Table 1 International Takotsubo Diagnostic Criteria (InterTAK Diagnostic Criteria) for takotsubo syndrome [14••]

1. Patients show transient ${ }^{\mathrm{a}}$ left ventricular dysfunction (hypokinesia, akinesia, dyskinesia) presenting as apical ballooning or midventricular, basal, or focal wall motion abnormalities. Right ventricular involvement can be present. Besides these regional wall motion patterns, transitions between all types can exist. The regional wall motion abnormality usually extends beyond a single epicardial vascular distribution; however, rare cases can exist where the regional wall motion abnormality is present in the subtended myocardial territory of a single coronary artery (focal TTS). ${ }^{\mathrm{b}}$

2. An emotional, physical, or combined trigger can precede the takotsubo syndrome event, but this is not obligatory.

3. Neurologic disorders (e.g., subarachnoid hemorrhage, stroke/transient ischemic attack, or seizures) as well as pheochromocytoma may serve as triggers for takotsubo syndrome.

4. New ECG abnormalities are present (ST-segment elevation, ST-segment depression, T-wave inversion, and QTc prolongation); however, rare cases exist without any ECG changes.

5. Levels of cardiac biomarkers (troponin and creatine kinase) are moderately elevated in most cases; significant elevation of brain natriuretic peptide is common.

6. Significant coronary artery disease is not a contradiction in takotsubo syndrome.

7. Patients have no evidence of infectious myocarditis. ${ }^{\text {b }}$

8. Postmenopausal women are predominantly affected.

\footnotetext{
${ }^{\mathrm{a}}$ Wall motion abnormalities may remain for a prolonged period of time or documentation of recovery may not be possible. For example, death before evidence of recovery is captured.

${ }^{\mathrm{b}}$ Cardiac magnetic resonance imaging is recommended to exclude infectious myocarditis and diagnosis confirmation of takotsubo syndrome.
} 
with high pre-test probability of TTS. Cardiac magnetic resonance imaging is especially valuable in patients with red flags of myocarditis. If the focal form is present, cardiac magnetic resonance imaging is recommended to rule out acute myocardial infarction (AMI) or myocarditis and to rule in TTS [53]. Absence of late-gadolinium enhancement and presence of myocardial edema are suggestive for TTS [54].

Clinically, TTS is indistinguishable from AMI. The InterTAK Diagnostic Score is a validated model for differentiation of TTS and ACS with high specificity and sensitivity [18]. Low InterTAK Diagnostic Score values indicate a high pre-test probability for ACS and high InterTAK Diagnostic Score values indicate a high pretest probability for TTS [18]. The InterTAK Diagnostic Score is available online at www.takotsubo-registry.com.

\section{Morphological Variants}

Takotsubo syndrome is classified in 4 distinctive phenotypes, depending on the region of LV wall motion abnormalities [27]. In the most typical (apical) TTS variant, which constitutes around $80 \%$ of cases, there is apical akinesis and basal hypercontractility [6, 27]. Atypical TTS types include the midventricular, basal, and focal form, and are present in $15 \%, 2 \%$, and $2 \%$ of cases respectively, [6, 27]. Over the past years, atypical TTS variants have been more frequently observed, indicating that awareness of such variants has expanded [27]. In all TTS types except focal, wall motion abnormalities are not solely confined to a single coronary artery vessel [••]. Right ventricular involvement is present in approximately onefourth of TTS cases [55]. The presence of right ventricular involvement has been suggested to present a severity marker for a more eventful clinical course and worse outcomes [56].

\section{Coronary Artery Disease}

Anterior myocardial infarction with wrap-around left anterior descending (LAD) artery can resemble an apical TTS phenotype. The "apical nipple sign" can help to distinguish TTS from anterior ST-segment elevation myocardial infarction (STEMI) in such cases [57].

One strongly held belief was that the diagnosis of TTS requires the absence of coronary artery disease (CAD). In the InterTAK Registry, $15.3 \%$ of patients had single-vessel and $7.8 \%$ of patients had multi-vessel disease, in whom the underlying CAD could not explain the wall motion abnormalities [58]. If TTS is suspected and $\mathrm{CAD}$ is present, a thorough comparison of angiography and left ventriculography should be performed to assess a potential perfusion-contraction mismatch [9]. This is of particular importance, as the limited knowledge on the coexistence of CAD and TTS might contribute to a substantial underdiagnosis of TTS. Whether CAD in TTS is causal or a bystander, and whether ad hoc percutaneous coronary intervention (PCI) or staged PCI should be performed in patients with TTS, warrants further investigation.

\section{Prognosis}

The short- and long-term sequelae of TTS were initially underestimated, because it was assumed that TTS is a harmless and self-healing condition. Recent data have demonstrated that TTS is associated with substantial risk of morbidity and mortality, with rates comparable to AMI $[6,59]$. The clinical course of TTS can be complicated by cardiac arrest, cardiogenic shock, or malignant arrhythmias [60-65]. The rate of death is $6 \%$ per patient-year and the major adverse cardiac and cerebrovascular event (MACCE) rate is $10 \%$ per patient-year [6].

Extra-cardiac predictors for adverse outcomes are male sex, physical triggering factors, and acute neurologic disorders. Cardiac predictors for adverse outcomes are troponin levels over 10 times the upper limit of the normal range, high BNP values, left ventricular ejection fraction (LVEF) below $45 \%$, moderate-to-severe mitral regurgitation, and right ventricular involvement $[6,65,66]$. Prognosis of TTS after emotional stress factors is generally favorable. Mortality is likely attributable to a combination of coexisting medical conditions and TTS [59,67]. Mortality is doubled for patients with physical triggers compared to patients with ACS [59]. The InterTAK Prognostic Score was established for risk prediction and incorporates covariates strongly associated with prognosis such as demographics, triggering factors, hemodynamics, and comorbidities [68].

The recurrence rate is estimated at $2 \%$ per patient-year, occurring over a period of 30 days to 10 years after documented wall motion recovery of the index event. Initially, the previously affected area was thought to be protected from recurrence, analogous to regional ischemic preconditioning [69]. However, data from multicenter registries consistently demonstrated that the same myocardial area can be affected at the index and recurrent event. Different wall motion patterns and triggering factors are observed in $20-30 \%$ of cases $[70,71]$. Neurologic or psychiatric disorders are independent predictors for TTS recurrence $[71,72]$. 


\section{Transience and Recovery of Wall Motion Abnormalities}

Transience of wall motion abnormalities and recovery of LV function have historically been acknowledged as central concepts of TTS [3, 32]. In the vast majority of cases, recovery of wall motion abnormalities and normalization LVEF can be observed within days to months after the acute event [73]. Factors associated with late recovery are male sex, LVEF below $45 \%$, and acute neurologic disorders [74].

However, ongoing chest discomfort, dyspnea, fatigue, and reduced exercise capability beyond the acute phase can persist for months after the TTS event despite normalization of myocardial function [75]. Structural and metabolic alterations of the myocardium were observed in the long-term, suggesting that TTS may be a persistent heart failure phenotype [76]. This novel concept of "incomplete recovery" may open an avenue for further research to uncover the mechanistic insights involved.

\section{Management}

Contemporary management of TTS is mainly empiric and relies on a combination of heart failure treatment and therapy of preexisting medical conditions. Randomized controlled trials have not been performed yet, and data from observational studies or case series have partially shown conflicting results [5]. In 2018, a management algorithm on acute and long-term management as well as management of complications was issued by an international expert panel (Level of evidence $\mathrm{C}$ ) to provide management approaches for patients with TTS [38••].

QT prolongation can be found in a substantial number of cases and can predispose the risk for development of torsade de pointes tachycardia [77-79]. QT-prolonging drugs need to be strictly avoided in TTS and monitoring for at least $48 \mathrm{~h}$ is recommended. $\beta$-adrenergic blockade is the standard treatment of choice for tachycardiac rhythms and temporary pacing can be considered in patients with atrioventricular block. Implantable cardioverter defibrillator (ICD) therapy to prevent sudden cardiac death in patients with severely reduced $\mathrm{EF}$ is not recommended due to normalization of ECG changes and LVEF within weeks after the event. Wearable defibrillators may be an option for patients with severely reduced LVEF $[38 \bullet \bullet, 80]$.

Cardiogenic shock in TTS can either develop from severe pump failure or left ventricular outflow tract obstruction (LVOTO) $[5,81]$. Catecholamines for hemodynamic stabilization should be avoided or administrated with great caution given the putative involvement in the pathophysiology [82]. Catecholamine therapy can aggravate LVOTO leading to further deterioration of cardiogenic shock. The calcium sensitizer levosimendan has been suggested to present a therapeutic alternative in such cases [83]. Mechanical support with microaxial pumps (Impella) might also represent a therapeutic option for
TTS patients with cardiogenic shock [84, 85]. The effectiveness of mechanical support with Impella is unknown, and all available data is based on case reports, which report excellent outcomes but might suffer from inherent publication bias [86].

LV thrombus may develop in regions of akinetic segments $[87,88]$. In these patients, therapeutic anticoagulation might be considered for 3 months [88]. Unlike in patients with cardiac aneurysm, lifelong anticoagulation is not recommended since wall motion abnormalities are transient [89]. Anticoagulation may also be considered in TTS patients with severe wall motion abnormalities to prevent LV thrombus formation.

Observational studies and meta-analyses consistently reported that short- and long-term treatment with $\beta$-blockers is not beneficial for mortality reduction nor recurrence prevention $[6,72,90-92]$. The use of angiotensin-converting enzyme (ACE) inhibitors or angiotensin receptor blockers (ARB) was associated with a survival benefit and less recurrence of events $[6,72]$. Cardiac rehabilitation may be beneficial for improvement of quality of life and to reduce episodes of ongoing chest pain [93]. CAD should be treated as directed by guideline [94]. Psychiatric counseling may be valuable for coexistent comorbidities and triggers.

\section{The Value of Registries}

In the past decades, we have learned major lessons from several single center and multicenter registries, which have contributed to an advanced understanding of the condition. The International Takotsubo Registry (InterTAK Registry) was established at the University Hospital Zurich, Switzerland, in 2011 to represent a unique multicenter database to raise awareness, provide insights regarding clinical features and outcomes, develop risk stratification tools for diagnosis and prognosis, and guide management for patients with TTS $[95,96]$. In 2015, the initial report of the InterTAK investigators was published in the New England Journal of Medicine extensively describing clinical features and outcomes of patients with TTS using data from 1750 patients derived from 26 sites in 9 countries [6]. Currently, more than 3500 patients from 56 active sites from 18 countries are included in the registry, making the InterTAK Registry the largest database for TTS patients.

\section{Conclusion}

Three decades after the seminal description of TTS, the knowledge base on clinical features, risk factors, and outcomes has remarkably expanded, and many myths and misconceptions were uncovered. Future investigations are needed to gain a better understanding of the pathophysiological mechanisms and to provide tailored therapeutic approaches to improve outcomes and prevent recurrences. 
Funding Open Access funding provided by Universität Zürich.

\section{Compliance with Ethical Standards}

Conflict of Interest Dr. Templin reports personal fees from Microport, Biotronic, Schnell Medical, and Amgen, outside the submitted work. The other authors declare that they have no conflict of interest.

Human and Animal Rights and Informed Consent This article does not contain any studies with human or animal subjects performed by any of the authors.

Open Access This article is licensed under a Creative Commons Attribution 4.0 International License, which permits use, sharing, adaptation, distribution and reproduction in any medium or format, as long as you give appropriate credit to the original author(s) and the source, provide a link to the Creative Commons licence, and indicate if changes were made. The images or other third party material in this article are included in the article's Creative Commons licence, unless indicated otherwise in a credit line to the material. If material is not included in the article's Creative Commons licence and your intended use is not permitted by statutory regulation or exceeds the permitted use, you will need to obtain permission directly from the copyright holder. To view a copy of this licence, visit http://creativecommons.org/licenses/by/4.0/.

\section{References}

Papers of particular interest, published recently, have been highlighted as:

- Of importance

•- Of major importance

1. Dote K, Sato H, Tateishi H, Uchida T, Ishihara M. Myocardial stunning due to simultaneous multivessel coronary spasms: a review of 5 cases. J Cardiol. 1991;21(2):203-14.

2. Sato H. Tako-tsubo-like left ventricular dysfunction due to multivessel coronary spasm. Clinical aspect of myocardial injury: from ischemia to heart failure Kodama K, Haze K, Hori M, Eds Kagakuhyoronsha Publishing Co, Tokyo. 1990:56-64 (Article in Japanese).

3. Akashi YJ, Goldstein DS, Barbaro G, Ueyama T. Takotsubo cardiomyopathy: a new form of acute, reversible heart failure. Circulation. 2008;118(25):2754-62.

4. Ghadri JR, Ruschitzka F, Luscher TF, Templin C. Takotsubo cardiomyopathy: still much more to learn. Heart. 2014;100(22):1804-12.

5. Kato K, Lyon AR, Ghadri JR, Templin C. Takotsubo syndrome: aetiology, presentation and treatment. Heart. 2017;103(18):1461-9.

6. Templin C, Ghadri JR, Diekmann J, Napp LC, Bataiosu DR, Jaguszewski M, et al. Clinical features and outcomes of takotsubo (stress) cardiomyopathy. N Engl J Med. 2015;373(10):929-38.

7. Tamis-Holland JE, Jneid H, Reynolds HR, Agewall S, Brilakis ES, Brown TM, et al. Contemporary diagnosis and management of patients with myocardial infarction in the absence of obstructive coronary artery disease: a scientific statement from the American Heart Association. Circulation. 2019;139(18):e891-908.

8. Niederseer D, Ghadri JR, Manka R, Templin C. Case report of a 66year-old woman with atypical takotsubo syndrome and concomitant coronary artery disease. BMJ Case Rep. 2020;13(2).

9. Napp LC, Ghadri JR, Bauersachs J, Templin C. Acute coronary syndrome or takotsubo cardiomyopathy: the suspect may not always be the culprit. Int J Cardiol. 2015;187:116-9.
10. Wittstein IS, Thiemann DR, Lima JA, Baughman KL, Schulman SP, Gerstenblith G, et al. Neurohumoral features of myocardial stunning due to sudden emotional stress. N Engl J Med. 2005;352(6):539-48.

11. Lyon AR, Citro R, Schneider B, Morel O, Ghadri JR, Templin C, et al. Pathophysiology of takotsubo syndrome: JACC state-of-theart review. J Am Coll Cardiol. 2021;77(7):902-21 This article provides a state-of-the-art review regarding the pathophysiology of takotsubo syndrome.

12. Sharkey SW, Lesser JR, Maron MS, Maron BJ. Why not just call it tako-tsubo cardiomyopathy: a discussion of nomenclature. J Am Coll Cardiol. 2011;57(13):1496-7.

13. Schlossbauer SA, Ghadri JR, Scherff F, Templin C. The challenge of takotsubo syndrome: heterogeneity of clinical features. Swiss Med Wkly. 2017;147:w14490.

14.• Ghadri JR, Wittstein IS, Prasad A, Sharkey S, Dote K, Akashi YJ, et al. International expert consensus document on takotsubo syndrome (part I): clinical characteristics, diagnostic criteria, and pathophysiology. Eur Heart J. 2018;39(22):2032-46 The takotsubo consensus document has been prepared in collaboration with the most experienced experts worldwide and is intended to provide a state-of-the-art review to guide clinicians in areas where evidence is still limited, new, and evolving.

15. Maron BJ, Towbin JA, Thiene G, Antzelevitch C, Corrado D, Arnett D, et al. Contemporary definitions and classification of the cardiomyopathies: an American Heart Association Scientific Statement from the Council on Clinical Cardiology, Heart Failure and Transplantation Committee; Quality of Care and Outcomes Research and Functional Genomics and Translational Biology Interdisciplinary Working Groups; and Council on Epidemiology and Prevention. Circulation. 2006;113(14):1807-16.

16. Elliott P, Andersson B, Arbustini E, Bilinska Z, Cecchi F, Charron P, et al. Classification of the cardiomyopathies: a position statement from the European Society Of Cardiology Working Group on Myocardial and Pericardial Diseases. Eur Heart J. 2008;29(2):270-6.

17. Luscher TF, Templin C. Is takotsubo syndrome a microvascular acute coronary syndrome? Towards of a new definition. Eur Heart J. 2016.

18. Ghadri JR, Cammann VL, Jurisic S, Seifert B, Napp LC, Diekmann J, et al. A novel clinical score (InterTAK Diagnostic Score) to differentiate takotsubo syndrome from acute coronary syndrome: results from the International Takotsubo Registry. Eur J Heart Fail. 2016.

19. Bybee KA, Prasad A, Barsness GW, Lerman A, Jaffe AS, Murphy JG, et al. Clinical characteristics and thrombolysis in myocardial infarction frame counts in women with transient left ventricular apical ballooning syndrome. Am J Cardiol. 2004;94(3):343-6.

20. Prasad A, Dangas G, Srinivasan M, Yu J, Gersh BJ, Mehran R, et al. Incidence and angiographic characteristics of patients with apical ballooning syndrome (takotsubo/stress cardiomyopathy) in the HORIZONS-AMI trial: an analysis from a multicenter, international study of ST-elevation myocardial infarction. Catheter Cardiovasc Interv. 2014;83(3):343-8.

21. Templin C, Napp LC, Ghadri JR. Takotsubo syndrome: underdiagnosed, underestimated, but understood? J Am Coll Cardiol. 2016;67(16):1937-40.

22. Citro R, Rigo F, Previtali M, Ciampi Q, Canterin FA, Provenza G, et al. Differences in clinical features and in-hospital outcomes of older adults with tako-tsubo cardiomyopathy. J Am Geriatr Soc. 2012;60(1):93-8.

23. Cammann VL, Szawan KA, Stahli BE, Kato K, Budnik M, Wischnewsky M, et al. Age-related variations in takotsubo syndrome. J Am Coll Cardiol. 2020;75(16):1869-77.

24. Sharkey SW, Shear W, Hodges M, Herzog CA. Reversible myocardial contraction abnormalities in patients with an acute noncardiac illness. Chest. 1998;114(1):98-105. 
25. Pavin D, Le Breton H, Daubert C. Human stress cardiomyopathy mimicking acute myocardial syndrome. Heart. 1997;78(5):509-11.

26. Ghadri JR, Sarcon A, Diekmann J, Bataiosu DR, Cammann VL, Jurisic S, et al. Happy heart syndrome: role of positive emotional stress in takotsubo syndrome. Eur Heart J. 2016.

27. Ghadri JR, Cammann VL, Napp LC, Jurisic S, Diekmann J, Bataiosu DR, et al. Differences in the clinical profile and outcomes of typical and atypical takotsubo syndrome: data from the International Takotsubo Registry. JAMA Cardiol. 2016;1(3):335-40.

28. Berends AMA, Buitenwerf E, de Krijger RR, Veeger N, van der HorstSchrivers ANA, Links TP, et al. Incidence of pheochromocytoma and sympathetic paraganglioma in the Netherlands: a nationwide study and systematic review. Eur J Intern Med. 2018;51:68-73.

29. Chatzizisis YS, Ziakas A, Feloukidis C, Paramythiotis D, Hadjimiltiades S, Iliadis A, et al. Pheochromocytoma crisis presenting with cardiogenic shock. Herz. 2014;39(1):156-60.

30. Prasad A, Lerman A, Rihal CS. Apical ballooning syndrome (TakoTsubo or stress cardiomyopathy): a mimic of acute myocardial infarction. Am Heart J. 2008;155(3):408-17.

31. Abe Y, Kondo M, Matsuoka R, Araki M, Dohyama K, Tanio H. Assessment of clinical features in transient left ventricular apical ballooning. J Am Coll Cardiol. 2003;41(5):737-42.

32. Bybee KA, Kara T, Prasad A, Lerman A, Barsness GW, Wright RS, et al. Systematic review: transient left ventricular apical ballooning: a syndrome that mimics ST-segment elevation myocardial infarction. Ann Intern Med. 2004;141(11):858-65.

33. Kawai S, Kitabatake A, Tomoike H. Guidelines for diagnosis of takotsubo (ampulla) cardiomyopathy. Circ J. 2007;71(6):990-2.

34. Schultz T, Shao Y, Redfors B, Sverrisdottir YB, Ramunddal T, Albertsson P, et al. Stress-induced cardiomyopathy in Sweden: evidence for different ethnic predisposition and altered cardiocirculatory status. Cardiology. 2012;122(3):180-6.

35. Madias JE. Why the current diagnostic criteria of takotsubo syndrome are outmoded: a proposal for new criteria. Int $\mathrm{J}$ Cardiol. 2014;174(3):468-70.

36. S YH. Clinical features and outcome of pheochromocytomainduced takotsubo syndrome: analysis of 80 published cases. Am J Cardiol. 2016;117(11):1836-44.

37. Ghadri JR, S YH, Luscher TF, Templin C. Pheochromocytoma triggers takotsubo syndrome. Eur Heart J. 2019.

38.• Ghadri JR, Wittstein IS, Prasad A, Sharkey S, Dote K, Akashi YJ, et al. International expert consensus document on takotsubo syndrome (part ii): diagnostic workup, outcome, and management. Eur Heart J. 2018;39(22):2047-62 The takotsubo consensus document has been prepared in collaboration with the most experienced experts worldwide and is intended to provide a state-ofthe-art review to guide clinicians in areas where evidence is still limited, new, and evolving.

39. Sposato LA, Hilz MJ, Aspberg S, Murthy SB, Bahit MC, Hsieh $\mathrm{CY}$, et al. Post-stroke cardiovascular complications and neurogenic cardiac injury: JACC state-of-the-art review. J Am Coll Cardiol. 2020;76(23):2768-85.

40. Kagiyama N, Sugahara M, Crago EA, Qi Z, Lagattuta TF, Yousef $\mathrm{KM}$, et al. Neurocardiac injury assessed by strain imaging is associated with in-hospital mortality in patients with subarachnoid hemorrhage. JACC Cardiovasc Imaging. 2020;13(2 Pt 2):535-46.

41. Krishnamoorthy V, Mackensen GB, Gibbons EF, Vavilala MS. Cardiac dysfunction after neurologic injury: what do we know and where are we going? Chest. 2016;149(5):1325-31.

42. Finsterer J, Wahbi K. CNS-disease affecting the heart: brain-heart disorders. J Neurol Sci. 2014;345(1-2):8-14.

43. Simon RP, Aminoff MJ, Benowitz NL. Changes in plasma catecholamines after tonic-clonic seizures. Neurology. 1984;34(2):255-7.

44. Hocker S, Prasad A, Rabinstein AA. Cardiac injury in refractory status epilepticus. Epilepsia. n.d.;54(3):518-22.
45. Finsterer J, Wahbi K. CNS disease triggering takotsubo stress cardiomyopathy. Int J Cardiol. 2014;177(2):322-9.

46. Desai R, Singh S, Patel U, Fong HK, Kaur VP, Varma Y, et al. Frequency of takotsubo cardiomyopathy in epilepsy-related hospitalizations among adults and its impact on in-hospital outcomes: a national standpoint. Int J Cardiol. 2020;299:67-70.

47. Ranieri M, Finsterer J, Bedini G, Parati EA, Bersano A. Takotsubo syndrome: clinical features, pathogenesis, treatment, and relationship with cerebrovascular diseases. Curr Neurol Neurosci Rep. 2018;18(5):20.

48. Dichtl W, Tuovinen N, Barbieri F, Adukauskaite A, Senoner T, Rubatscher A, et al. Functional neuroimaging in the acute phase of takotsubo syndrome: volumetric and functional changes of the right insular cortex. Clin Res Cardiol. 2020;109(9):1107-13.

49. Templin C, Hanggi J, Klein C, Topka MS, Hiestand T, Levinson RA, et al. Altered limbic and autonomic processing supports brain-heart axis in takotsubo syndrome. Eur Heart J. 2019;40(15):1183-7.

50. Klein C, Hiestand T, Ghadri JR, Templin C, Jancke L, Hanggi J. Takotsubo syndrome - predictable from brain imaging data. Sci Rep. 2017;7(1):5434.

51. Wittstein IS. Stress cardiomyopathy: a syndrome of catecholaminemediated myocardial stunning? Cell Mol Neurobiol. 2012;32(5): 847-57.

52. Lyon AR, Bossone E, Schneider B, Sechtem U, Citro R, Underwood SR, et al. Current state of knowledge on takotsubo syndrome: a Position Statement from the Taskforce on Takotsubo Syndrome of the Heart Failure Association of the European Society of Cardiology. Eur J Heart Fail. 2016;18(1):8-27.

53. Kato K, Kitahara H, Fujimoto Y, Sakai Y, Ishibashi I, Himi T, et al. Prevalence and clinical features of focal takotsubo cardiomyopathy. Circ J. 2016;80(8):1824-9.

54. Eitel I, von Knobelsdorff-Brenkenhoff F, Bernhardt P, Carbone I, Muellerleile K, Aldrovandi A, et al. Clinical characteristics and cardiovascular magnetic resonance findings in stress (takotsubo) cardiomyopathy. JAMA. 2011;306(3):277-86.

55. Haghi D, Athanasiadis A, Papavassiliu T, Suselbeck T, Fluechter S, Mahrholdt $\mathrm{H}$, et al. Right ventricular involvement in takotsubo cardiomyopathy. Eur Heart J. 2006;27(20):2433-9.

56. Citro R, Bossone E, Parodi G, Rigo F, Nardi F, Provenza G, et al. Independent impact of RV involvement on in-hospital outcome of patients with takotsubo syndrome. JACC Cardiovase Imaging. 2016;9(7):894-5.

57. Desmet W, Bennett J, Ferdinande B, De Cock D, Adriaenssens T, Coosemans M, et al. The apical nipple sign: a useful tool for discriminating between anterior infarction and transient left ventricular ballooning syndrome. Eur Heart J Acute Cardiovasc Care. 2014;3(3):264-7.

58. Napp LC, Cammann VL, Jaguszewski M, Szawan KA, Wischnewsky M, Gili S, et al. Coexistence and outcome of coronary artery disease in takotsubo syndrome. Eur Heart J. 2020;41(34):3255-68.

59. Ghadri JR, Kato K, Cammann VL, Gili S, Jurisic S, Di Vece D, et al. Long-term prognosis of patients with takotsubo syndrome. J Am Coll Cardiol. 2018;72(8):874-82.

60. Gili S, Cammann VL, Schlossbauer SA, Kato K, D'Ascenzo F, Vece DD, et al. Cardiac arrest in takotsubo syndrome: results from the InterTAK Registry. Eur Heart J. 2019.

61. Di Vece D, Citro R, Cammann VL, Kato K, Gili S, Szawan KA, et al. Outcomes associated with cardiogenic shock in takotsubo syndrome. Circulation. 2019;139(3):413-5.

62. Stiermaier T, Eitel C, Desch S, Fuernau G, Schuler G, Thiele H, et al. Incidence, determinants and prognostic relevance of cardiogenic shock in patients with takotsubo cardiomyopathy. Eur Heart J Acute Cardiovasc Care. 2016;5(6):489-96.

63. Almendro-Delia M, Nunez-Gil IJ, Lobo M, Andres M, Vedia O, Sionis A, et al. Short- and long-term prognostic relevance of 
cardiogenic shock in takotsubo syndrome: results from the RETAKO Registry. JACC Heart Fail. 2018;6(11):928-36.

64. El-Battrawy I, Santoro F, Stiermaier T, Moller C, Guastafierro F, Novo G, et al. Prevalence, management, and outcome of adverse rhythm disorders in takotsubo syndrome: insights from the international multicenter GEIST registry. Heart Fail Rev. 2020;25(3):50511.

65. Murakami T, Yoshikawa T, Maekawa Y, Ueda T, Isogai T, Konishi $Y$, et al. Characterization of predictors of in-hospital cardiac complications of takotsubo cardiomyopathy: multi-center registry from Tokyo CCU Network. J Cardiol. 2014;63(4):269-73.

66. Brinjikji W, El-Sayed AM, Salka S. In-hospital mortality among patients with takotsubo cardiomyopathy: a study of the National Inpatient Sample 2008 to 2009. Am Heart J. 2012;164(2):215-21.

67. Sharkey SW, Maron BJ. Survival after takotsubo Revisited. J Am Coll Cardiol. 2018;72(8):883-4.

68. Wischnewsky MB, Candreva A, Bacchi B, Cammann VL, Kato K, Szawan KA, et al. Prediction of short- and long-term mortality in takotsubo syndrome: the InterTAK Prognostic Score. Eur J Heart Fail. 2019;21(11):1469-72.

69. Xu B, Williams PD, Brown M, Macisaac A. Takotsubo cardiomyopathy: does recurrence tend to occur in a previously unaffected ventricular wall region? Circulation. 2014;129(7):e339-40.

70. El-Battrawy I, Santoro F, Stiermaier T, Moller C, Guastafierro F, Novo G, et al. Incidence and clinical impact of recurrent takotsubo syndrome: results from the GEIST Registry. J Am Heart Assoc. 2019;8(9):e010753.

71. Kato K, Di Vece D, Cammann VL, Micek J, Szawan KA, Bacchi $\mathrm{B}$, et al. Takotsubo recurrence: morphological types and triggers and identification of risk factors. J Am Coll Cardiol. 2019;73(8): 982-4.

72. Singh K, Carson K, Usmani Z, Sawhney G, Shah R, Horowitz J. Systematic review and meta-analysis of incidence and correlates of recurrence of takotsubo cardiomyopathy. Int J Cardiol. 2014;174(3):696-701.

73. Tsuchihashi K, Ueshima K, Uchida T, Oh-mura N, Kimura K, Owa $\mathrm{M}$, et al. Transient left ventricular apical ballooning without coronary artery stenosis: a novel heart syndrome mimicking acute myocardial infarction. Angina Pectoris-Myocardial Infarction Investigations in Japan. J Am Coll Cardiol. 2001;38(1):11-8.

74. Jurisic S, Gili S, Cammann VL, Kato K, Szawan KA, D'Ascenzo F, et al. Clinical predictors and prognostic impact of recovery of wall motion abnormalities in takotsubo syndrome: results from the International Takotsubo Registry. J Am Heart Assoc. 2019;8(21): e011194.

75. Singh K. Tako-Tsubo syndrome: issue of incomplete recovery and recurrence. Eur J Heart Fail. 2016;18(12):1408-10.

76. Scally C, Rudd A, Mezincescu A, Wilson H, Srivanasan J, Horgan $\mathrm{G}$, et al. Persistent long-term structural, functional, and metabolic changes after stress-induced (takotsubo) cardiomyopathy. Circulation. 2018;137(10):1039-48.

77. Migliore F, Zorzi A, Peruzza F, Perazzolo Marra M, Tarantini G, Iliceto $\mathrm{S}$, et al. Incidence and management of life-threatening arrhythmias in takotsubo syndrome. Int J Cardiol. 2013;166(1):2613.

78. Moller C, Eitel C, Thiele H, Eitel I, Stiermaier T. Ventricular arrhythmias in patients with takotsubo syndrome. J Arrhythm. 2018;34(4):369-75.

79. Mitsuma W, Kodama M, Ito M, Tanaka K, Yanagawa T, Ikarashi $\mathrm{N}$, et al. Serial electrocardiographic findings in women with takotsubo cardiomyopathy. Am J Cardiol. 2007;100(1):106-9.

80. Peters S, Klein HU. WCD LifeVest: risk stratification in a case of Tako-Tsubo cardiomyopathy with QT interval prolongation. Herz. 2012;37(2):219-21.
81. De Backer O, Debonnaire P, Gevaert S, Missault L, Gheeraert P, Muyldermans L. Prevalence, associated factors and management implications of left ventricular outflow tract obstruction in takotsubo cardiomyopathy: a two-year, two-center experience. BMC Cardiovasc Disord. 2014;14:147.

82. Templin C, Ghadri JR, Napp LC. Takotsubo (stress) cardiomyopathy. N Engl J Med. 2015;373(27):2689-91.

83. Santoro F, Ieva R, Ferraretti A, Ienco V, Carpagnano G, Lodispoto $\mathrm{M}$, et al. Safety and feasibility of levosimendan administration in takotsubo cardiomyopathy: a case series. Cardiovasc Ther. 2013;31(6):e133-7.

84. Attisano T, Silverio A, Prota C, Briguori C, Galasso G, Citro R. Impella in takotsubo syndrome complicated by left ventricular outflow tract obstruction and severe mitral regurgitation. ESC Heart Fail. 2020;7(1):306-10.

85. Nakamura M, Nakagaito M, Hori M, Ueno H, Kinugawa K. A case of takotsubo cardiomyopathy with cardiogenic shock after influenza infection successfully recovered by IMPELLA support. J Artif Organs. 2019;22(4):330-3.

86. Mariani S, Richter J, Pappalardo F, Belohlavek J, Lorusso R, Schmitto JD, et al. Mechanical circulatory support for takotsubo syndrome: a systematic review and meta-analysis. Int J Cardiol. 2020;316:31-9.

87. Ding KJ, Cammann VL, Szawan KA, Stahli BE, Wischnewsky M, Di Vece D, et al. Intraventricular thrombus formation and embolism in takotsubo syndrome: insights from the International Takotsubo Registry. Arterioscler Thromb Vasc Biol. 2020;40(1):279-87.

88. Santoro F, Stiermaier T, Tarantino N, De Gennaro L, Moeller C, Guastafierro F, et al. Left ventricular thrombi in takotsubo syndrome: incidence, predictors, and management: results from the GEIST (German Italian Stress Cardiomyopathy) Registry. J Am Heart Assoc. 2017;6(12).

89. Kurisu S, Inoue I, Kawagoe T, Ishihara M, Shimatani Y, Nakama $\mathrm{Y}$, et al. Incidence and treatment of left ventricular apical thrombosis in Tako-tsubo cardiomyopathy. Int J Cardiol. 2011;146(3):e5860 .

90. Isogai T, Matsui H, Tanaka H, Fushimi K, Yasunaga H. Early betablocker use and in-hospital mortality in patients with takotsubo cardiomyopathy. Heart. 2016;102(13):1029-35.

91. Dias A, Franco E, Koshkelashvili N, Bhalla V, Pressman GS, Hebert K, et al. Antiplatelet therapy in takotsubo cardiomyopathy: does it improve cardiovascular outcomes during index event? Heart Vessel. 2016;31(8):1285-90.

92. Santoro F, Ieva R, Musaico F, Ferraretti A, Triggiani G, Tarantino $\mathrm{N}$, et al. Lack of efficacy of drug therapy in preventing takotsubo cardiomyopathy recurrence: a meta-analysis. Clin Cardiol. 2014;37(7):434-9.

93. Wu CM, McKeon J, Abbott JD, Jiang L, Wu WC. Referral to cardiac rehabilitation and outcomes for patients with takotsubo cardiomyopathy. J Cardiopulm Rehabil Prev. 2019;39(3):E8-E11.

94. Knuuti J, Wijns W, Saraste A, Capodanno D, Barbato E, FunckBrentano C, et al. 2019 ESC Guidelines for the diagnosis and management of chronic coronary syndromes. Eur Heart J. 2020;41(3): 407-77.

95. Ghadri JR, Cammann VL, Templin C. The International Takotsubo Registry: rationale, design, objectives, and first results. Heart Fail Clin. 2016;12(4):597-603.

96. Ghadri JR, Templin C. The InterTAK Registry for takotsubo syndrome. Eur Heart J. 2016;37(37):2806-8.

Publisher's Note Springer Nature remains neutral with regard to jurisdictional claims in published maps and institutional affiliations. 